\title{
STRATEGIC MANAGEMENT CREATIVITY AND FIRM SURVIVAL: AN EMPIRICAL INVESTIGATION OF THE EXPORTING FASHION ACCESSORIES BUSINESS IN THAILAND
}

\author{
Ploychompoo Kittikunchotiwut, Mahasarakham Business School, Maasarakham University, Thailand \\ Phapruke Ussahawanitchakit, Mahasarakham Business School, Mahasarakham University, Thailand \\ Karun Pratoom, Mahasarakham Business School, Mahasarakham University, Thailand
}

dx.doi.org/10.18374/JABE-13-3.6

\begin{abstract}
The objective of this study is examine the relationships among five dimensions of strategic management creativity, business excellence effectiveness, organization innovation success, goal achievement efficiency through firm survival which have flexible orientation as moderators. Strategic management creativity consists of new management method experimentation, proactive organizational development implementation, modern human resource management establishment, integrative performance evaluation presentation, and value added working system enhancement. In addition, this research investigates the antecedents of strategic management creativity, including long-term vision, organization learning intelligence, firm resource readiness, business experience usefulness, and environmental complexity with the moderating effect of transformational culture. Here, 314 exporting firms from the exporting fashion accessories businesses in Thailand were chosen as the sample of the study. The results indicate that the relationships among some dimension of strategic management creativity, business excellence effectiveness, organizational innovation success, goal achievement efficiency, and firm survival are positively significant. In addition, organizational innovation success has a significant positive impact on business excellence effectiveness, goal achievement efficiency, and firm survival. Furthermore, organizational innovation success, and goal achievement efficiency have a significant positive impact on firm survival. Moreover, the moderator of flexibility orientation among the relationships of new management method experimentation, goal achievement efficiency, proactive organizational development implementation, firm survival, integrative performance evaluation presentation, and value added working system enhancement are significant. Also, the moderator of transformational culture among the relationships of firm resource readiness, environmental complexity, and value added working system enhancement is significant. Potential discussion with the research results is effectively implemented in the study. Theoretical and managerial contributions are explicitly provided. A conclusion, suggestions, and directions for future research are highlighted.
\end{abstract}

Keywords: Strategic Management Creativity, New Management Method Experimentation, Proactive Organizational Development Implementation, Modern Human Resource Management Establishment, Integrative Performance Evaluation Presentation, Value Added Working System Enhancement, Business Excellence Effectiveness, Organization Innovation Success, Goal Achievement Efficiency, Firm Survival, Long-Term Vision, Organization Learning Intelligence, Firm Resource Readiness, Business Experience Usefulness, Environmental Complexity, Transformational Culture, Flexibility Orientation 